\title{
Countries versus industries in Europe: A normative portfolio approach
}

Received: 23rd May, 2005

\section{Javier Estrada*}

is Associate Professor at the IESE Business School in Barcelona, Spain, and co-editor of the Emerging Markets Review. He has published extensively on topics related to investing and is the author of the book Finance in a Nutshell. He has an MS in finance and a PhD in economics, both from the University of Illinois at Urbana-Champaign.

\section{Mark Kritzman}

is President and CEO of Windham Capital Management, LLC. He has written numerous articles for academic and professional journals and is the author of six books including Puzzles of Finance and The Portable Financial Analyst. He has an MBA with distinction from New York University.

\section{Simon Myrgren}

is a senior research associate at State Street Associates, Cambridge, MA. He is primarily involved in research concerning portfolio allocation and portfolio risk models. Before joining State Street Associates he devised mathematical and computational models for theoretical physics applications at the University of California, Berkeley. He received his PhD in theoretical chemistry in August 2004.

\section{Sébastien Page}

is Vice President at State Street Associates, Boston, MA, where he is responsible for asset allocation and risk management. In 2003 he won the Bernstein Fabozzi/Jacobs Levy Award for Best Article in the Journal of Portfolio Management. He holds an M.Sc. in finance from Sherbrooke University, Canada, and is a CFA charterholder.

*IESE Business School, Av. Pearson 21, 08034 Barcelona, Spain

Tel: +34 93253 4200; Fax: +34 93253 4343; e-mail: jestrada@iese.edu

\begin{abstract}
The relative benefits of country diversification and industry diversification are critical for investors, portfolio managers and investment banks. The unification of Europe has had a substantial impact on these relative benefits and the ultimate goal of this paper is to evaluate their temporal evolution. It is found that, although a country approach outperformed an industry approach in the early 1990s under three different performance measures, the opposite was the case in the late 1990s and early 2000s. It is also found that this shift does not seem to be a temporary phenomenon associated with the TMT bubble. Overall, the results validate both the increasing emphasis on industry diversification and the recent reorganisation of research departments of investment banks, previously organised along country lines and currently organised along industry lines. There seems to be little question that, in Europe, industry expertise has become more important than country expertise.
\end{abstract}

Keywords: country effects, industry effects, diversification, bootstrapping

\section{Introduction}

In recent years, European countries have become increasingly integrated, particularly after the launch of the euro at the beginning of 1999. Economic, fiscal, monetary and financial integration 
are taking place at a fast pace, and their impact is evident both in Europe and in the rest of the world.

This increasing integration of European economies and markets has many and far-reaching implications for the financial industry. For example, consider that, over the last few years, investment banks, institutional investors and asset managers have restructured their research and trading departments, previously organised along country lines, to accord with industry delineations; see Bolliger (2001) and Galati and Tsatsaronis (2001).

Consistent with this recent emphasis on industries over countries, recent surveys indicate that 75 per cent of European equity managers believe in the superiority of allocation strategies based on industries and 10 per cent in allocation strategies based on countries. Back in 1997, these proportions were 20 per cent and 50 per cent, respectively. ${ }^{1}$

The issue addressed in this paper is whether diversification across countries or across industries has a larger impact on portfolio performance. More precisely, it asks whether portfolio managers and investors should first determine the European country weights (and then pick stocks from each country), or first determine the European industry weights (and then pick stocks from each industry). The answer to this question follows from the relative impact of countries and industries on portfolio performance and is by and large empirical.

This relative importance of country effects and industry effects, in turn, not only dictates the first step of a portfolio optimisation process but also the optimal organisation of research departments in the financial industry. Should research departments hire industry experts or country experts? That depends on whether country-specific knowledge is more or less important than industry-specific expertise and that, again, is by and large an empirical issue.

Needless to mention, this debate is critical not just for the European financial industry. International investment banks, brokerage houses and asset managers that have large operations in Europe need to organise them as efficiently as possible. Furthermore, international investors that invest in European equity need to determine the first step of a top-down allocation approach. In short, the issue addressed in this paper and the conclusions drawn from the analysis have far-reaching implications for the international financial industry as well as for international investors.

In order to determine the relative impact of countries and industries on portfolio performance, the paper departs from most of the literature in at least one critical way. The analysis is normative rather than positive. In other words, the analysis does not focus on what investors have done in the past in order to draw lessons for the future. Rather, it focuses on the choices investors should emphasise if they are skilful, and the choices they should avoid if they lack skill.

The main results can be summarised as follows. Over the whole 1989-2003 period, country diversification and industry diversification provided investors with very similar benefits. This result, however, conceals an important shift in the relative benefits of these two approaches. In the early 1990s, the country approach dominated the industry approach; in the late 1990s and early 2000s, the opposite was the case.

The relative benefits of country and industry diversification are measured by focusing on the impact of these strategies on dispersion in returns, dispersion in risk-adjusted returns and the value of exchange options. The results of all three methods largely point in the same 
direction. Furthermore, these results are not driven by the TMT (technology, media and telecommunications) bubble, and apply to both European and EMU countries.

The rest of the paper is organised as follows. The second section discusses the issue at stake, reviewing the evidence on country diversification versus industry diversification (at both the international level and the European level), as well as the normative and positive approaches that can be used to answer the main issues addressed in this paper. The third section describes the data and methodology. The fourth section reports and discusses the results, and the final section summarises the main results and their implications. An Appendix with a figure and tables concludes the paper.

\section{The issue at stake}

Two issues are tackled in this section. First, the evidence on country effects and industry effects is discussed, both at the international level and more specific to the purpose at the European level. Then, the normative and positive approaches are discussed, and the authors explain why they believe that the former is a better tool for analysing the issue addressed in this paper.

\section{Country diversification and industry diversification: International evidence}

The trend toward increasing integration of European economies and markets has revived interest on a topic critical for both academics and practitioners, namely, the relative benefits of country diversification and industry diversification. These two portfolio approaches obviously do not preclude each other. Because not all countries exhibit the same industry composition, country diversification also provides some diversification across industries. Similarly, because industries are scattered around countries, industry diversification also provides some diversification across countries. Many studies attempt to separate these two effects and determine whether diversifying across countries is more or less beneficial than diversifying across industries.

Although the evidence on this topic is vast and contradictory, the consensus seems to be that, over time, industry effects have grown in importance relative to country effects. That is not to say that the former are more important than the latter. That issue remains controversial and depends, to a large extent, on the sample period and the countries and industries considered in the different studies. But the trend in the relative importance of these two effects is hardly disputed; that is, the impact of industries on portfolio performance has been growing over time relative to the impact of countries. ${ }^{2}$

Early studies on the topic, such as Solnik (1974), concluded that country diversification provides more risk reduction than industry diversification. This finding had an important impact on practice, leading traditional top-down managers to adopt a country-selection approach as the key tactical decision when optimising portfolios. The superiority of country effects over industry effects was subsequently confirmed by several studies, such as Grinold et al. (1989), Griffin and Karolyi (1998), Baca et al. (2000), Gerard et al. (2002), L'Her et al. (2002), Carrieri et al. (2003), Isakov and Sonney (2003) and Phylaktis and Xia (2004), among others. It should be noted that all these studies consider international (not just European) markets. ${ }^{3}$

It should also be noted that in all these studies the dominance of country effects over industry effects is on average over the whole sample period considered in each study. This is important, because many of the more recent studies show an upward 
trend in the impact of industry effects, which in some cases eventually overcome country effects. In other words, country allocations dominate industry allocations on average, but not necessarily in every period.

This growing impact of industry effects relative to country effects is well documented. When the former began to overcome the latter, however, is highly dependent on the countries and industries considered in the different studies. Baca et al. (2000) report that, although country effects dominated industry effects between 1983 and 1999, by the end of this period both effects had become statistically indistinguishable from each other. Cavaglia et al. (2000) report that, although country factors dominated industry factors between 1989 and 1996, the latter overcame the former early in 1997. L'Her et al. (2002) find that countries dominated industries between 1992 and 1998, and that the opposite was the case during 1999-2000. Isakov and Sonney (2003) find that countries dominated industries between 1997 and early 2000, and that the opposite was the case during the rest of the year 2000. Phylaktis and Xia (2004) show that countries dominated industries during the whole 1992-2001 period with two caveats: first, there was a major increase in the industry effect beginning in 2000, with over one-fifth of the industries having a larger impact on performance than the average country; and secondly, the results vary across regions.

There seems to be no consensus on the reasons behind the increase in the relative importance of industry effects. One possibility is that it follows from the increase in cross-country correlations, sometimes loosely explained as the result of globalisation (and European integration). Carrieri et al. (2003), for example, show that the average conditional correlation across countries has increased relative to that across industries.

Another possibility is that it follows from the impact of the TMT bubble. In this view, the increasing importance of industry effects is largely driven by the large swing in TMT stocks. Brooks and Del Negro (2002) argue that this is indeed the case and advise portfolio managers to stick to the traditional strategy of country diversification. Kritzman and Page (2003), using a different methodology, also find that the rise in industry effects appears to be driven by the swing in TMT stocks. Phylaktis and Xia (2004), however, find that the increasing relevance of industry effects is robust to the removal of TMT stocks from their sample and therefore conclude that the shift is not temporary.

All in all, the international evidence seems to suggest that:

1. Country effects have been on average more important than industry effects.

2. Industry effects have over time grown in importance relative to country effects.

3. There is disagreement about whether industry effects have overcome country effects (and if so, when).

4. There is disagreement about the impact of the TMT bubble on the importance of industry effects.

\section{Country diversification and industry diversification: Europe}

No region of the world has

experimented with an integration process anywhere close to that of European countries. The gradual harmonisation of policies is slowly but surely increasing the synchronisation of economies and markets, which begs the question whether country-diversification strategies have become less effective. The restructuring of the financial industry, now organised largely along industry 
lines, and the beliefs of European equity managers in the superiority of industry stratification would seem to indicate so. This section therefore discusses the evidence on this issue, focusing on studies that restrict their sample to European markets.

Early studies largely agree on the dominance of country effects over industry effects. Drummen and Zimmermann (1992) find that country factors are twice as important as industry factors and advise analysts to focus on countries rather than industries. Heston and Rouwenhorst (1994, 1995), in two influential articles that introduce the methodology that became standard for this topic, also find that country factors are more important than industry factors. Beckers et al. (1996), using the Heston-Rouwenhorst methodology, also report results that support the superiority of the country approach.

By the mid-1990s, however, the increasing integration of European markets became evident. Freimann (1998) reports a dramatic increase in cross-country correlations, from 0.23 in the second half of the 1970s to 0.60 in the first half of the 1990s. Beckers (1999) reports a statistically significant upward trend in cross-country correlations. And Aggarwal et al. (2003), using a novel cointegrating technique, report an increasing degree of integration across markets, particularly during the 1997-98 period. $^{4}$

This increasing integration of European markets, in turn, led practitioners and academics to wonder whether a country-allocation approach was still the best strategy. As an answer, Rouwenhorst (1999) shows that, despite the impact of EMU, country effects still dominate industry effects on average over the 1978-98 period, and also in each of the four five-year sub-periods. Moerman (2004), however, finds that, although country and industry factors had roughly the same impact on portfolio performance during the 1995-98 period, the latter outperformed the former during the more recent 1999-2002 period. He also finds that these results are robust to the exclusion of TMT stocks and therefore argues that the country-diversification strategy has become outdated. ${ }^{5}$

Overall, the European evidence seems to be quite consistent with the more general international evidence. ${ }^{6}$ If anything, the difference seems to be one of degree. In other words, correlations across European markets seem to have increased more than across international markets, and therefore the decreasing relative impact of country effects is more pronounced in Europe than in the rest of the world.

\section{Normative analyses and positive analyses}

Many studies that deal with assessing the impact of alternative stratification methods suffer from a common flaw: they fail to disentangle the consequences of investor behaviour from the opportunity set offered by capital markets. In response to this problem, Kritzman and Page (2002, 2003) introduced a normative approach that controls for investor behaviour and enables them to isolate the opportunity set. This approach, which is followed in this paper, is discussed at length in their articles, and it is reviewed only very briefly here.

A positive approach analyses the historical performance of managed portfolios. It therefore confounds two separate influences, namely, the investment opportunities available to investors and the choices made by those investors. In other words, these studies provide a joint test of investor behaviour and capital market opportunities, and 
reveal not what investors should (or should not) do, but rather what they chose to do.

The widely used methodology proposed by Heston and Rouwenhorst (1994), although normative, is not free from problems, either. First, it rules out interaction effects between countries and industries; that is, a company belonging to a given country and industry is assumed to have exposure only to that country and to that industry. Secondly, it assumes equal exposures for countries and for sectors, both of which are fixed over time. And thirdly, it is not always the case that the pure (country or industry) portfolios resulting from this methodology are obtainable; that is, investing in a country or an industry implies exposures that would need to be offset in order to obtain pure country or industry effects.

The Kritzman and Page (2002, 2003) methodology disentangles the impact of investor behaviour from the opportunities offered by the relevant assets. Their approach reveals the choices that investors should emphasise if they are skilful, or the choices they should avoid if they lack skill. This approach makes it possible to isolate the opportunity sets associated with country allocation and industry allocation from the behaviour and choices of investors. ${ }^{7}$ Moreover, their approach yields investable portfolios.

\section{Data and methodology}

This section tackles two issues. First, it describes the sample and the procedure used to generate the custom country and industry indices. Then it discusses the bootstrapping methodology.

\section{Data}

The sample is constructed from the MSCI database of over 30,000 securities. From this database, all the stocks that belong to the 16 countries and 24 industries relevant to the study are selected. ${ }^{8}$ This filter produces 1,172 stocks, for which returns and market capitalisations between December 1988 and December 2003 are gathered.

Table A1 in the Appendix shows the 16 countries and 24 industries in the sample, as well as the number of stocks in each country and industry. The table shows that the UK and Capital Goods are the country and industry that contribute the largest number of stocks to the sample (415 and 197, respectively). Austria and Semiconductors \& Semiconductors Equipment, on the other hand, are the country and industry that contribute the least (14 and 3, respectively).

In order to ensure internal consistency between each broader component and its constituents, the own custom indices are constructed for countries and industries.

To illustrate the construction of the indices, consider Deutsche Bank, a German company that belongs to the Diversified Financials industry. The weight of Deutsche Bank in the index for the German market equals the market capitalisation of this bank divided by the sum of the market capitalisations of all the companies in the index for this country. The weight of Deutsche Bank in the Diversified Financials index, in turn, equals the market capitalisation of this bank divided by the sum of the market capitalisations of all the companies in the index for this industry. The same approach is used to build the indices for all 16 countries and 24 industries. As shown in Table A1, the correlation between the custom indices for countries and industries and their respective MSCI indices is over 0.9 in virtually all cases.

All returns (which account for both capital gains and dividends) and market capitalisations are measured in dollars. 
The reasons for this are threefold. First, portfolios of stocks are formed from different countries (or from industries in different countries), and it would be meaningless to aggregate returns in different currencies. Secondly, it would not be correct to eliminate a country-specific risk factor (currency risk), and at the same time preserve all the industry-specific risk factors. And thirdly, although currency risk can be hedged, it does not have to be; some investors may choose not to hedge it, and some others may even choose to amplify it.

\section{Methodology}

The approach is based on bootstrapping, a procedure that consists of generating samples by randomly selecting observations from a dataset.

Bootstrapping differs from Monte Carlo simulation in that the former draws randomly from an empirical sample, whereas the latter draws randomly from a theoretical distribution. Bootstrapping is used to generate random portfolios that represent the available opportunity set.

The country-allocation simulations are performed as follows. Sixteen country returns with replacement 10,000 times are randomly selected from a sample of 16 countries. When a return is selected, its market capitalisation is also selected, so that each randomly selected country is weighted according to its market capitalisation. Industry and individual security weights within each country are fixed according to their relative capitalisation. This procedure generates 10,000 portfolios for each of the years between 1989 and 2003 (which vary randomly by their country weights), which are subsequently ranked by cumulative performance.

The industry-allocation simulation is performed in a similar way. Twenty-four industry returns with replacement 10,000 times are randomly selected from a sample of 24 industries. Again, when a return is selected, its market capitalisation is also selected, so that each selection is weighted according to its market capitalisation. Country and individual security weights within each industry are fixed according to their relative capitalisation. This procedure generates 10,000 portfolios for each of the years between 1989 and 2003 (which vary randomly by their industry weights), which are subsequently ranked by cumulative performance.

\section{The evidence}

The results are discussed in this section. The central question, the relative impact of country effects and industry effects in Europe, is tackled from three different angles: dispersion in returns, dispersion in risk-adjusted returns and option prices. Whether the results are influenced by the TMT bubble is also explored; whether they change over sub-periods; whether they exhibit any temporal trend; and whether they hold for European countries or less generally only for EMU countries.

\section{Dispersion in returns}

This section addresses the extent to which a skilful portfolio manager or investor can improve upon average performance by engaging in either country allocation or industry allocation. In this regard, dispersion in returns is valuable for skilful investors because higher dispersion corresponds to a higher potential for above-average performance.

Table 1 shows that the dispersion in returns arising from country allocation (1.6 per cent to -1.6 per cent for the upper and the lower 5 th percentiles, and 0.7 per cent to -0.7 per cent for the 
Table 1 Full sample period (1989-2003)

\begin{tabular}{rlccccc}
\hline & \multicolumn{2}{c}{ Returns } & \multicolumn{2}{c}{ Sharpe ratios } & \multicolumn{2}{c}{ Option prices } \\
\cline { 2 - 7 } Percentile & CA (\%) & IA (\%) & CA & IA & CA (\%) & IA (\%) \\
\hline 5 & 1.6 & 1.7 & 9.2 & 10.4 & 2.3 & 2.3 \\
25 & 0.7 & 0.7 & 3.7 & 4.4 & 1.9 & 1.8 \\
75 & -0.7 & -0.7 & -3.8 & -4.3 & 3.1 & 1.8 \\
95 & -1.6 & -1.7 & -9.0 & -10.3 & 1.7 & 1.8 \\
\hline
\end{tabular}

CA: Country allocation; IA: Industry allocation. Annual figures.

upper and the lower quartiles) is virtually identical to that arising from industry allocation (1.7 per cent to -1.7 per cent for the upper and the lower 5th percentiles, and 0.7 per cent to -0.7 per cent for the upper and the lower quartiles). This indicates that, on average over the whole sample period, country selection and industry selection provided skilful investors with similar opportunities to obtain above-average performance.

Note, however, that these numbers are averages over the whole sample period. It may well be the case that country allocation was superior to industry allocation during some period, that the opposite was the case over some other period, and that, on average, these two effects cancel each other out. This issue is explored in more detail later.

\section{Dispersion in risk-adjusted returns}

It could be argued that dispersion in returns is not an appropriate criterion, because it ignores the risk of country and industry allocations. In order to account for both the risk and the return of the portfolios that arise from country allocation and industry allocation, this section examines dispersion in risk-adjusted returns. Risk-adjusted returns are measured with the Sharpe ratio, defined as the return of each portfolio net of the three-month US Treasury Bill, divided by the volatility of the portfolio.

Table 1 shows that the dispersion in risk-adjusted returns arising from industry allocation (10.4 to -10.3 for the upper and the lower 5 th percentiles, and 4.4 to -4.3 for the upper and the lower quartiles) is slightly higher than that arising from country allocation (9.2 to -9.0 for the upper and the lower 5 th percentiles, and 3.7 to -3.8 for the upper and the lower quartiles). This indicates that, on average over the whole sample period, industry diversification provided skilful investors with slightly better opportunities to obtain above-average risk-adjusted returns.

Again, these averages over the whole sample period may be hiding temporal variation in the relative impact of industry and country allocation. These issues are therefore explored in more detail later.

\section{Option pricing}

This section considers a variation of the Black-Scholes model to price an exchange option, which gives the holder the right to exchange one risky asset for another. More precisely, the exchange option priced is one that enables its owner to exchange median performance for top-quartile (and top-5th percentile) performance, and another to exchange bottom-quartile (and bottom-5th percentile) performance for median performance. (As illustrated in the Appendix, relative dispersion between a top-percentile portfolio and a bottom-percentile portfolio do not 
Table 2 Full sample period (1989-2003), no TMT stocks

\begin{tabular}{rlrrrrr}
\hline & \multicolumn{2}{c}{ Returns } & \multicolumn{2}{c}{ Sharpe ratios } & \multicolumn{2}{c}{ Option prices } \\
\cline { 2 - 6 } Percentile & CA (\%) & IA (\%) & CA & IA & CA (\%) & IA (\%) \\
\hline 5 & 1.6 & 1.5 & 10.2 & 10.8 & 1.8 & 1.7 \\
25 & 0.6 & 0.6 & 4.2 & 4.3 & 1.4 & 2.1 \\
75 & -0.6 & -0.6 & -4.2 & -4.5 & 2.3 & 1.8 \\
95 & -1.6 & -1.5 & -10.5 & -10.5 & 2.4 & 1.6 \\
\hline
\end{tabular}

CA: Country allocation; IA: Industry allocation. Annual figures.

always coincide with the relative values of options to exchange these portfolios.)

The option price follows from the expressions

$$
\begin{aligned}
& E O=N\left(d_{1}\right)-N\left(d_{2}\right) \\
& d_{1}=\frac{\ln \left(V_{\mathrm{P}} / V_{\mathrm{M}}\right)+(1 / 2) \sigma^{2} t}{\sigma \sqrt{t}} \\
& d_{2}=d_{1}-\sigma \sqrt{t}
\end{aligned}
$$

where $E O$ denotes the value (price) of the exchange option; $N$ is the cumulative normal distribution; $V_{\mathrm{P}}$ and $V_{\mathrm{M}}$ are the starting value of the chosen percentile portfolio and the starting value of the median portfolio, respectively; $\sigma$ is the relative volatility between $V_{\mathrm{P}}$ and $V_{\mathrm{M}}$ (also known as tracking error); and $t$ is the time remaining to expiration (as a fraction of a year). Expressions (1)-(3) yield the value of an exchange option assuming that income is reinvested and the starting value of the portfolios is 1 .

The results in Table 1 show that the value of an option to become a top (upper 5th percentile) country allocator is identical to that of an option to become a top (again, upper 5 th percentile) industry allocator. In both cases, the option value is equal to 2.3 per cent of the asset value of the portfolio. Similarly, the value of an option to exchange bottom (5th percentile) performance for median performance is virtually identical for country and industry allocation, being 1.7 per cent of the asset value of the portfolio in the first case and 1.8 per cent in the second.

\section{The impact of the TMT bubble}

As discussed above, a possible explanation for the rising impact of the benefits of industry diversification is that it is a temporary phenomenon associated with the TMT bubble. In order to test this hypothesis, all TMT stocks are removed from the sample and dispersion in returns, dispersion in risk-adjusted returns and option prices are re-estimated. The revised results are displayed in Table 2 .

Table 2 shows that the dispersion in returns arising from country allocation (1.6 per cent to -1.6 per cent for the upper and the lower 5 th percentiles, and 0.6 per cent to -0.6 per cent for the upper and the lower quartiles) is virtually identical to that arising from industry allocation ( 1.5 per cent to -1.5 per cent for the upper and the lower 5 th percentiles, and 0.6 per cent to -0.6 per cent for the upper and the lower quartiles). The slight advantage of industry diversification over country diversification shown in Table 1 is reversed when TMT stocks are removed from the sample, but in both cases the differences are negligible. In other words, after accounting for the impact of the TMT bubble, on average and over the whole sample period, it remains the case that country diversification and industry diversification provided skilful investors 
Table 3 Sub-periods (1989-96 and 1997-2003)

\begin{tabular}{lcccccc}
\hline & \multicolumn{2}{c}{ Returns } & \multicolumn{2}{c}{ Sharpe ratios } & \multicolumn{2}{c}{ Option prices } \\
\cline { 2 - 7 } Percentile & CA (\%) & IA (\%) & CA & IA & CA (\%) & IA (\%) \\
\hline Panel A: $1989-96$ & & & & & & \\
5 & 2.1 & 1.4 & 21.4 & 14.0 & 3.0 & 1.9 \\
25 & 0.9 & 0.6 & -9.7 & 5.3 & 2.0 & 1.0 \\
75 & -0.9 & -0.6 & -9.5 & -5.7 & 2.8 & 1.4 \\
95 & -2.1 & -1.4 & -19.8 & -13.0 & 2.2 & 1.5 \\
Panel B: $1997-2003$ & 2.5 & 3.2 & 9.9 & 13.9 & 0.9 & 3.0 \\
5 & 1.0 & 1.3 & 4.1 & 5.7 & 1.2 & 2.9 \\
25 & -1.0 & -1.3 & -4.1 & -5.7 & 1.2 & 2.6 \\
75 & -2.5 & -3.2 & -10.1 & -13.8 & 1.5 & 3.5 \\
95 & & &
\end{tabular}

CA: Country allocation; IA: Industry allocation. Annual figures.

with virtually identical opportunities to obtain above-average performance.

Table 2 also shows that the dispersion in risk-adjusted returns arising from industry allocation (10.8 to -10.5 for the upper and the lower 5 th percentiles, and 4.3 to -4.5 for the upper and the lower quartiles) remains slightly higher than that arising from country allocation (10.2 to -10.5 for the upper and the lower 5 th percentiles, and 4.2 to -4.2 for the upper and the lower quartiles). The small advantage of industry allocation shown in Table 1, however, becomes even smaller after removing the TMT stocks from the sample.

\section{Sub-periods}

As discussed above, the evidence in the literature quite clearly indicates that industry effects have been increasing over time relative to country effects. This hypothesis is tested in three different ways, one of which is discussed in this section. The first test consists of splitting the sample period into two sub-periods, 1989-96 and 1997-2003, and re-estimating dispersion in returns, dispersion in risk-adjusted returns, and option prices for each sub-sample. The results are displayed in Panels A and B of Table 3.
As the numbers clearly show, the change between the first and the second periods is quite dramatic. During the first period, country allocation generated substantially more dispersion in both returns and risk-adjusted returns than industry allocation. Similarly, the options approach indicates a higher value for the exchange options related to country allocation both to obtain top performance and to avoid bottom performance.

In the second period, however, the superiority of the industry approach is clear. The dispersions in returns and risk-adjusted returns arising from industry allocation are substantially larger than those arising from country allocation. Similarly, exchange options to achieve top performance and to avoid bottom performance as an industry allocator are more valuable than those to achieve top performance and to avoid bottom performance as a country allocator.

It should be noted that these results are not influenced by the TMT bubble. Table A2 in the Appendix shows that the superiority of the country approach during the 1989-96 period, as well as the superiority of the industry approach during the 1997-2003 period, are robust to the exclusion of TMT stocks. 


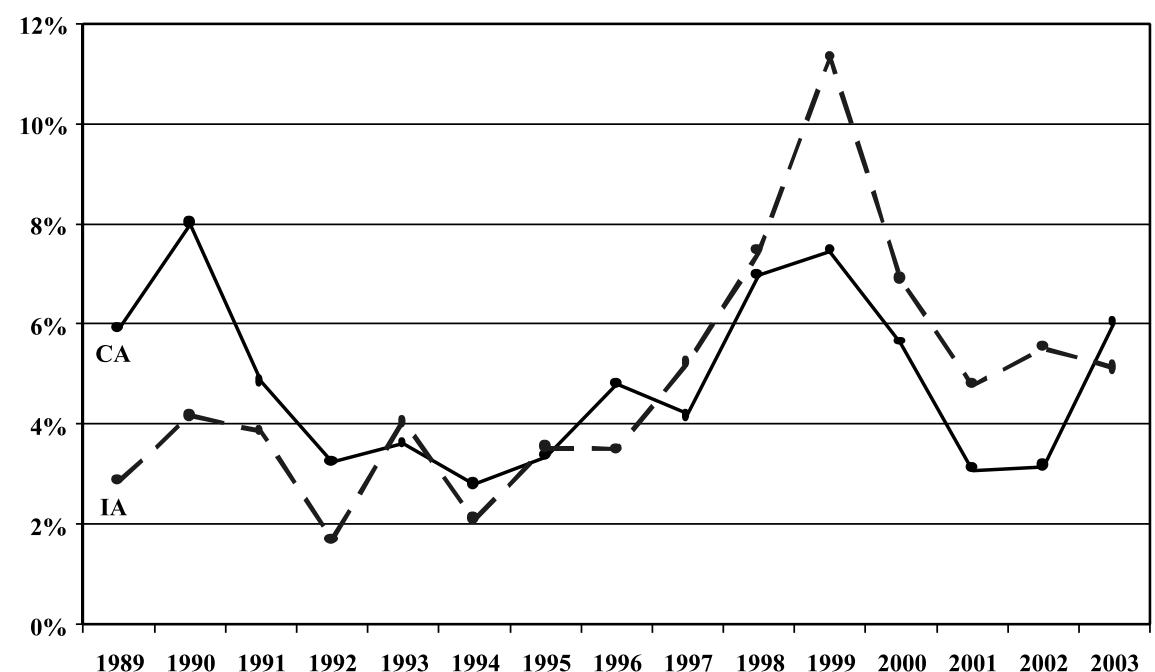

Figure 1 Dispersion in returns

Essentially, the results confirm the shift in the relative importance of industry effects and country effects; country diversification is clearly superior in the earlier period and industry diversification is clearly superior in the later period. The results, however, follow from a very different approach to those common in the literature and therefore support the rising impact of industry effects.

\section{Trends}

The temporal variation in the relative impact of country and industry allocation is an important issue, and it is explored further from another angle, namely, by assessing the temporal evolution of the dispersion in returns generated by the country approach and the industry approach. More precisely, for each of the years between 1989 and 2003, the spread between top-quartile performance and bottom-quartile performance for both country allocation and industry allocation are calculated. The results are displayed in Figure 1.

The figure shows that country allocation generated more dispersion in returns than did industry allocation, both at the beginning and at the end of the sample period, but not in every year. In fact, industry allocation generated more dispersion in returns in eight out of 15 years, with country allocation generating more dispersion in the other seven years. Furthermore, although the dispersion in country allocation does not exhibit a clear trend, that of industry allocation seems to exhibit an overall upward trend. Note that, although the dispersion in returns generated by country allocation begins and ends at the same level, that of industry allocation increases by 80 per cent.

In order to assess the influence of the TMT bubble, all annual dispersions in returns after removing the TMT stocks from the sample are recalculated. The results displayed in Figure 2 show that, although country allocation generated more dispersion in returns at the beginning of the period, the opposite was the case by the end of the period (albeit by a very small margin). Furthermore, it is again the case that, although the dispersion in returns arising from country allocation does not exhibit a clear trend over time, the dispersion in returns arising from industry allocation seems to display 


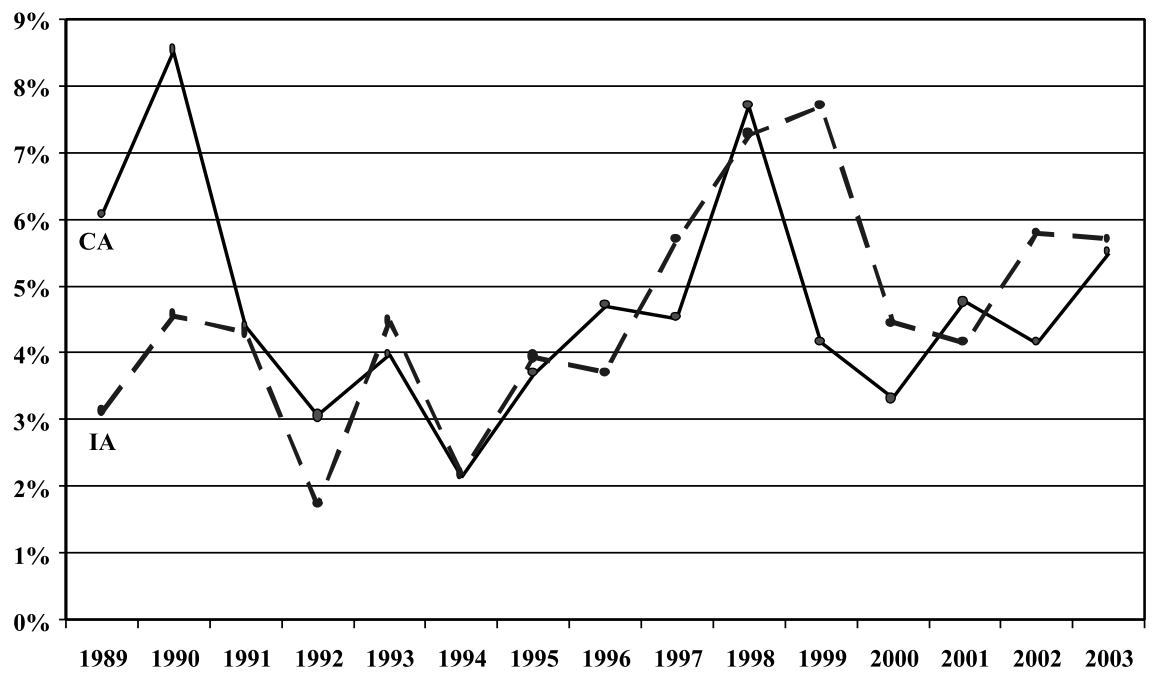

Figure 2 Dispersion in returns, no TMT stocks

an overall upward trend. (Note that the dispersion in returns generated by country allocation falls between the beginning and the end of the sample period, whereas that of industry allocation rises.) As was the case before, industry allocation generates more dispersion in returns than country allocation in eight years out of 15 , and the opposite is the case in the other seven years.

Perhaps unsurprisingly, the removal of TMT stocks, and therefore the impact of the TMT bubble, is most clear in the years 1998-99. Figure 1 shows that in 1998 industry allocation provided slightly more dispersion in returns than country allocation. Figure 2, however, shows that, after removing the TMT stocks, country allocation actually provided slightly more dispersion than industry allocation. In 1999, the removal of TMT stocks caused a much larger fall in the dispersion in returns arising from industry allocation than in that arising from country allocation.

\section{EMU countries}

Table A1 in the Appendix shows that the sample includes European countries that do not belong to the EMU, such as Denmark, Norway, Switzerland and the UK. It is therefore explored whether the results are robust to the exclusion of these countries from the sample. In other words, the relative impact of country and industry allocation is assessed, focusing only on the countries that belong to the EMU.

Table 4 shows that the main results still hold. For the whole sample period, panel A shows that the dispersion in returns arising from country allocation and industry allocation are virtually identical to each other. Thus, on average over the whole sample period, country allocation and industry allocation provided skilful investors with similar opportunities to obtain above-average performance. Also as was the case before with all countries in the sample, the dispersion in risk-adjusted returns arising from industry allocation is slightly higher than that arising from country allocation.

Panels B and C also confirm the previous results. During the 1989-96 period, a country approach provided investors with higher dispersion in both returns and risk-adjusted returns. During 


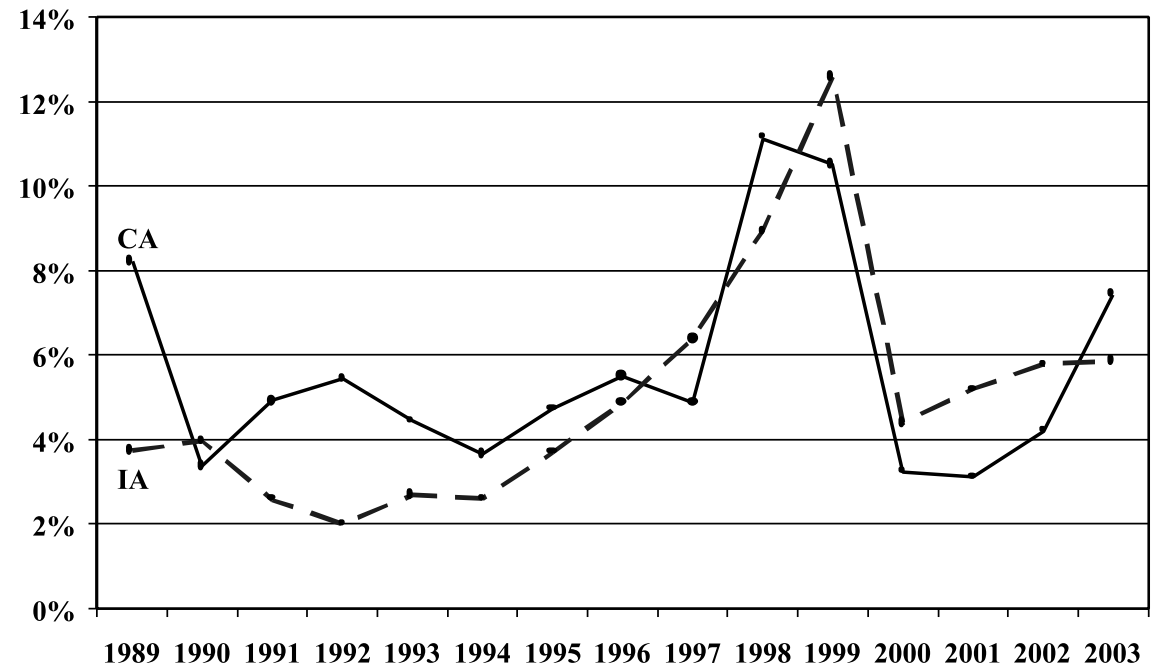

Figure 3 EMU countries, dispersion in returns

Table 4 EMU countries

\begin{tabular}{|c|c|c|c|c|c|c|}
\hline \multirow[b]{2}{*}{ Percentile } & \multicolumn{2}{|l|}{ Returns } & \multicolumn{2}{|c|}{ Sharpe ratios } & \multicolumn{2}{|c|}{ Option prices } \\
\hline & CA (\%) & IA (\%) & CA & IA & CA (\%) & IA (\%) \\
\hline \multicolumn{7}{|c|}{ Panel A: 1989-2003 } \\
\hline 5 & 1.9 & 1.8 & 8.4 & 9.2 & 2.7 & 2.0 \\
\hline 25 & 0.8 & 0.7 & 3.6 & 3.7 & 2.1 & 2.4 \\
\hline 75 & -0.8 & -0.7 & -3.5 & -3.8 & 2.7 & 2.6 \\
\hline 95 & -1.9 & -1.8 & -8.8 & -8.9 & 3.0 & 2.4 \\
\hline \multicolumn{7}{|c|}{ Panel B: 1989-1996 } \\
\hline 5 & 2.3 & 1.5 & 17.6 & 11.8 & 2.9 & 1.2 \\
\hline 25 & 0.9 & 0.6 & 6.8 & 4.6 & 1.7 & 1.9 \\
\hline 75 & -0.9 & -0.6 & -6.9 & -4.8 & 2.2 & 1.1 \\
\hline 95 & -2.3 & -1.4 & -16.8 & -11.0 & 1.8 & 1.2 \\
\hline \multicolumn{7}{|c|}{ Panel C: 1997-2003 } \\
\hline 5 & 3.2 & 3.5 & 10.4 & 12.9 & 5.0 & 2.8 \\
\hline 25 & 1.2 & 1.3 & 4.3 & 5.1 & 3.2 & 1.4 \\
\hline 75 & -1.3 & -1.4 & -4.2 & -5.4 & 4.0 & 1.8 \\
\hline 95 & -3.0 & -3.2 & -10.6 & -12.2 & 1.9 & 2.4 \\
\hline
\end{tabular}

CA: Country allocation; IA: Industry allocation. Annual figures.

the 1997-2003 period, however, the opposite was the case; that is, the industry approach provided investors with better opportunities to obtain both above-average performance and above-average risk-adjusted performance.

Table A3 in the Appendix shows that these results are largely unaffected by the TMT bubble. Although the sample without TMT stocks now shows that, on average for the whole sample period, industry allocation provided a slightly higher dispersion in returns (the opposite is the case in panel A of Table 4), it still remains the case that industry allocation provided slightly higher dispersion in risk adjusted returns, that country allocation dominates industry allocation during the 1989-96 period, and that industry allocation dominates country allocation during the 1997-2003 period.

Figure 3 shows that the temporal evolution of the dispersion in returns generated by country allocation and 
Table 5 Introduction of the euro

\begin{tabular}{|c|c|c|c|c|c|c|}
\hline \multirow[b]{2}{*}{ Percentile } & \multicolumn{2}{|c|}{ Returns } & \multicolumn{2}{|c|}{ Sharpe ratios } & \multicolumn{2}{|c|}{ Option prices } \\
\hline & CA (\%) & IA (\%) & CA & IA & CA (\%) & IA (\%) \\
\hline \multicolumn{7}{|c|}{ Panel A: Europe, before euro } \\
\hline 5 & 2.0 & 1.6 & 23.0 & 15.8 & 1.9 & 1.3 \\
\hline 25 & 0.8 & 0.6 & 9.0 & 5.9 & 2.5 & 1.6 \\
\hline 75 & -0.8 & -0.6 & -9.8 & -6.3 & 2.1 & 1.8 \\
\hline 95 & -1.9 & -1.5 & -20.8 & -14.4 & 2.2 & 1.6 \\
\hline \multicolumn{7}{|c|}{ Panel B: Europe, after euro } \\
\hline 5 & 2.9 & 3.9 & 11.1 & 15.0 & 4.9 & 1.4 \\
\hline 25 & 1.1 & 1.5 & 4.6 & 6.0 & 3.9 & 1.5 \\
\hline 75 & -1.1 & -1.6 & -4.5 & -6.1 & 2.7 & 2.6 \\
\hline 95 & -2.8 & -3.8 & -11.2 & -15.0 & 2.2 & 4.0 \\
\hline \multicolumn{7}{|c|}{ Panel C: EMU, before euro } \\
\hline 5 & 2.3 & 1.7 & 20.6 & 14.2 & 3.2 & 1.8 \\
\hline 25 & 0.9 & 0.7 & 7.5 & 5.5 & 1.5 & 1.2 \\
\hline 75 & -0.9 & -0.7 & -8.1 & -5.7 & 2.9 & 1.1 \\
\hline 95 & -2.3 & -1.7 & -18.8 & -13.3 & 1.1 & 0.9 \\
\hline \multicolumn{7}{|c|}{ Panel D: EMU, after euro } \\
\hline 5 & 3.4 & 4.0 & 12.3 & 14.2 & 2.4 & 1.6 \\
\hline 25 & 1.3 & 1.6 & 5.1 & 5.7 & 2.0 & 2.6 \\
\hline 75 & -1.4 & -1.7 & -4.9 & -6.0 & 1.4 & 4.9 \\
\hline 95 & -3.3 & -3.7 & -12.6 & -13.5 & 2.6 & 3.1 \\
\hline
\end{tabular}

CA: Country allocation; IA: Industry allocation. Annual figures.

industry allocation is very similar to that with all countries in the sample (Table 4). Country allocation dominates at the beginning and at the end of the sample period, though to a lesser degree at the end. Although the dispersion in returns generated by country allocation falls between the beginning and the end of the period, that generated by industry allocation increases by almost 60 per cent. It also remains the case that industry allocation provides more dispersion in returns in some (but not in all) years, particularly by the end of the sample period. Figure A1 in the Appendix shows that these results are very similar when TMT stocks are removed from the sample.

In short, restricting the inquiry to EMU countries does not seem to affect the main results substantially. It remains the case that (1) on average over the whole sample period both approaches generate similar dispersion in returns; and (2) that average results over the whole sample period conceal the superiority of the country approach in the first half of the sample, and that of the industry approach in the second half.

\section{Introduction of the euro}

As a final test of the consistency of the results, two other sub-periods are considered, in this case before and after the introduction of the euro, on 1st January, 1999. The results for all European countries and for EMU countries only are displayed in Table 5 .

Panels A and B of Table 5 show that, when considering all European countries, the basic results still hold. In this case, before the introduction of the euro, country allocation generated a higher dispersion in both returns and risk-adjusted return than did industry allocation. After the introduction of the euro, however, the opposite is the case. Panels C and D show that, when restricting the sample to EMU countries, these basic results still hold. Finally, Table A5 in the Appendix shows that all these results hold when TMT stocks are excluded from the sample. 


\section{Conclusions}

The economic, fiscal, monetary and financial integration of European countries that began in the 1990s, and deepened with the arrival of the euro in 1999, has many and far-reaching implications, not just for Europe, but for the rest of the world as well. This paper has focused on the impact of integration on investors and the financial industry in general.

The impact of European integration is critical for investors and asset managers, because it largely dictates the optimal portfolio allocation strategy. It is also important for investment banks and brokerage houses because the optimal organisation of research departments depends on the relative impact of country and industry effects on portfolio performance. Put differently, the impact of integration determines whether country expertise is more or less valuable than industry expertise.

In order to determine the relative impact of countries and industries on portfolio performance, this paper departs from most of the literature in at least one critical way. The analysis is normative rather than positive, thus determining what investors should do. In other words, the analysis determines the choices investors should emphasise if they are skilful and those they should avoid if they lack skill.

Importantly, the results are not based on managed portfolio returns but on potential returns. As Samuelson has famously stated, we only have one sample of history. For this reason, a bootstrapping procedure is used which enables many thousand samples that history could have generated to be considered, thus eliminating the confounding influence of investor choice in the one sample observed.

The results can be summarised as follows. Over the whole 1989-2003 period, country allocation and industry allocation had a similar impact on the dispersion of potential performance. This result, however, conceals an important shift in the relative impact of these two approaches. In the early 1990s, the country approach dominated the industry approach, but the opposite was the case in the late 1990s and early 2000s.

The relative impact of country and industry allocation was measured by focusing on the impact of these strategies on dispersion in returns, dispersion in risk-adjusted returns and the value of exchange options. The results of all three methods largely point in the same direction. These results are not driven by the TMT bubble, and apply to both European and EMU countries.

Overall, the results validate the recent emphasis on industries over countries in Europe. Perhaps this emphasis should not be entirely surprising. In the US, no portfolio manager would think of allocation across states; industry allocation is the obvious approach. Perhaps the current situation in Europe is not quite like that. But the results clearly indicate that, should current trends continue, country allocation in Europe will eventually make just as much sense as state allocation in the US.

\section{Acknowledgments}

We should like to thank participants at the 2005 FMA meetings (Siena, Italy) for their helpful comments. The views expressed below and any errors that may remain are entirely the authors'.

\section{Notes}

1. These numbers, reported by Galati and Tsatsaronis (2001), come from surveys of asset managers conducted on behalf of Merrill Lynch.

2. Some practitioners believe, however, that country effects began to make a comeback late in 2002; see Sesit (2003).

3. Heston and Rouwenhorst $(1994,1995)$ played a 
crucial role in the development of this literature, proposing the methodology that eventually became standard for this topic. Because their sample is restricted to European markets, however, their contribution is discussed in the next section.

4. Fratzscher (2002) reports similar results showing that European markets have become increasingly integrated since 1996.

5. Phylaktis and Xia (2004), reporting separate results for Europe, show somewhat contradicting results. Using one methodology, they find that countries clearly outperformed industries during the 1992-99 period, but only slightly during the $2000-01$ period. Using a different methodology, however, they find that industries did outperform countries during the 2000-01 period.

6. This of course should not be entirely surprising. European markets as a group make up a large proportion of international markets and therefore influence the international results substantially.

7. Using this approach, Estrada et al. (2003) show that country diversification is more effective than industry diversification in emerging markets.

8. The MSCI classification makes a distinction between industries and industry groups, providing 62 indices for the former and 24 for the latter. This study focuses on the 24 industry groups but, simply for ease of exposition, refers to them as industries.

9. Dispersion in returns, however, is harmful for unskilful investors, because it exposes them to below-average performance.

\section{References}

Aggarwal, R., Lucey, B. and Muckley, C. (2003) 'Dynamics of Equity Market Integration in Europe: Evidence of Changes Over Time and With Events', Working Paper.

Baca, S., Garbe, B. and Weiss, R. (2000) 'The Rise of Sector Effects in Major Equity Markets', Financial Analysts Journal, September-October, 34-40.

Beckers, S. (1999) 'Investment Implications of a Single European Capital Market', Journal of Portfolio Management, Spring, 9-17.

Beckers, S., Connor, G. and Curds, R. (1996) 'National versus Global Influences on Equity Returns', Financial Analysts Journal, March-April, 31-9.

Bolliger, G. (2001) 'The Characteristics of Individual Analysts' Forecasts in Europe', FAME Research Paper 33.

Brooks, R. and Del Negro, M. (2002) 'The Rise in Comovement across National Stock Markets: Market Integration or IT Bubble?' Federal Reserve Bank of Atlanta, Working Paper 2002-17a.

Carrieri, F., Errunza, V. and Sarkissian, S. (2003) 'The Dynamics of Geographic versus Sectoral Diversification: A Causal Explanation', Working Paper.

Cavaglia, S., Brightman, C. and Aked, M. (2000) 'The Increasing Importance of Industry Factors', Financial Analysts Journal, September-October, 41-54.
Drummen, M. and Zimmermann, H. (1992) 'The Structure of European Stock Returns', Financial Analysts Journal, July-August, 15-26.

Estrada, J., Kritzman, M. and Page, S. (2003) 'Countries versus Industries in Emerging Markets: A Normative Portfolio Approach', Working Paper.

Fratzscher, M. (2002) 'Financial Market Integration in Europe: On the Effects of EMU on Stock Markets', International Journal of Finance and Economics, 7, 165-93.

Freimann, E. (1998) 'Economic Integration and Country Allocation in Europe', Financial Analysts Journal, September-October, 32-41.

Galati, G. and Tsatsaronis, K. (2001) 'The Impact of the Euro on Europe's Financial Markets', BIS Working Paper 100.

Gerard, B., Hillion, P. and de Roon, F. (2002) 'International Portfolio Diversification: Industry, Country, and Currency Effects Revisited', Working Paper.

Griffin, J. and Karolyi, A. (1998) 'Another Look at the Role of the Industrial Structure of Markets for International Diversification Strategies', Journal of Financial Economics, 50, 351-73.

Grinold, R., Rudd, A. and Stefek, D. (1989) 'Global Factors: Fact or Fiction?' Journal of Portfolio Management, Fall, 79-88.

Heston, S. and Rouwenhorst, G. (1994) 'Does Industrial Structure Explain the Benefits of International Diversification?' Journal of Financial Economics, 36, 3-27.

Heston, S. and Rouwenhorst, G. (1995) 'Industry and Country Effects in International Stock Returns', Journal of Portfolio Management, Spring, 53-8.

Isakov, D. and Sonney, F. (2003) 'Are Practitioners Right? On the Relative Importance of Industrial Factors in International Stock Returns', Working Paper.

Kritzman, M. and Page, S. (2002) 'Asset Allocation Versus Security Selection: Evidence from Global Markets', Journal of Asset Management, 3, 202-12.

Kritzman, M. and Page, S. (2003) 'The Hierarchy of Investment Choice: A Normative Interpretation', Journal of Portfolio Management, Summer, 11-24.

L'Her, J.-F., Sy, O. and Tnani, M. (2002) 'Country, Industry, and Risk Factor Loadings in Portfolio Management', Journal of Portfolio Management, Summer, 70-9.

Moerman, G. (2004) 'Diversification in Euro Area Stock Markets: Country versus Industry', European Central Bank Working Paper 327.

Phylaktis, K. and Xia, L. (2004) 'The Changing Role of Industry and Country Effects in the Global Equity Markets', Working Paper.

Rouwenhorst, G. (1999) 'European Equity Markets and the EMU', Financial Analysts Journal, May-June, $57-64$.

Sesit, M. (2003) 'Geography Matters in Steering Stock Prices', Wall Street Journal Europe, 9th May.

Solnik, B. (1974) 'Why Not Diversify Internationally Rather than Domestically?' Financial Analysts Journal, $30,48-54$. 


\section{Appendix}

Tables

Table A1 Countries and industries

\begin{tabular}{lrllrr}
\hline Country & Stocks & Rho & Industries & Stocks & Rho \\
\hline Austria & 14 & 0.92 & Automobiles \& Components & 28 & 0.93 \\
Belgium & 47 & 0.96 & Banks & 59 & 0.97 \\
Denmark & 42 & 0.94 & Capital Goods & 197 & 0.99 \\
Finland & 18 & 0.98 & Commercial Services \& Supplies & 45 & 0.92 \\
France & 98 & 0.98 & Consumer Durables \& Apparel & 100 & 0.93 \\
Germany & 141 & 0.97 & Diversified Financials & 102 & 0.87 \\
Greece & 28 & 0.98 & Energy & 24 & 0.98 \\
Ireland & 22 & 0.90 & Food \& Staples Retailing & 18 & 0.96 \\
Italy & 76 & 0.96 & Food, Beverage \& Tobacco & 74 & 0.99 \\
Netherlands & 74 & 0.97 & Health Care Equipment \& Services & 16 & 0.88 \\
Norway & 22 & 0.97 & Hotels, Restaurants \& Leisure & 26 & 0.90 \\
Portugal & 16 & 0.91 & Household \& Personal Products & 13 & 0.98 \\
Spain & 33 & 0.99 & Insurance & 37 & 1.00 \\
Sweden & 42 & 0.98 & Materials & 115 & 0.99 \\
Switzerland & 84 & 0.97 & Media & 49 & 0.96 \\
UK & 415 & 0.98 & Pharmaceuticals \& Biotechnology & 14 & 0.95 \\
Average & & 0.99 & Real Estate & 58 & 0.95 \\
& & & Retailing & 49 & 0.96 \\
& & Semiconductors \& Semiconductor Equipment & 3 & 0.67 \\
& & Software \& Services & 26 & 0.96 \\
& & & Technology Hardware \& Equipment & 49 & 0.99 \\
& & Telecommunication Services & 6 & 0.93 \\
& & & Transportation & 39 & 0.91 \\
& & Utilities & 25 & 0.93 \\
\hline
\end{tabular}

Regions and industries are based on the MSCl classification. 'Stocks' indicates the number of stocks from each country or industry in the sample. 'Rho' indicates the correlation between the custom index for each country and industry and its respective $\mathrm{MSCl}$ index.

Table A2 Sub-periods (1989-96 and 1997-2003), no TMT stocks

\begin{tabular}{llccccc}
\hline & \multicolumn{2}{c}{ Returns } & \multicolumn{2}{c}{ Sharpe ratios } & \multicolumn{2}{c}{ Option prices } \\
\cline { 2 - 6 } Percentile & CA (\%) & IA (\%) & CA & IA & CA (\%) & IA (\%) \\
\hline Panel A: $1989-96$ & & & & & & \\
5 & 2.1 & 1.5 & 21.5 & 14.1 & 3.4 & 2.4 \\
25 & 0.9 & 0.6 & -9.8 & 5.6 & 2.3 & 2.1 \\
75 & -0.9 & -0.6 & -9.2 & -5.8 & 2.6 & 2.1 \\
95 & -2.1 & -1.5 & -20.2 & -13.4 & 2.4 & 1.7 \\
Panel B: $1997-2003$ & 2.3 & 2.7 & 10.9 & 14.1 & 1.7 & 2.6 \\
5 & 0.9 & 1.1 & 4.4 & 5.8 & 1.6 & 1.6 \\
25 & -1.0 & -1.1 & -4.6 & -5.9 & 1.9 & 2.0 \\
75 & -2.2 & -2.7 & -11.0 & -13.7 & 2.3 & 0.7 \\
95 & & &
\end{tabular}

CA: Country allocation; IA: Industry allocation. Annual figures. 
Estrada, Kritzman, Myrgren and Page

Table A3 EMU countries, no TMT stocks

\begin{tabular}{|c|c|c|c|c|c|c|}
\hline \multirow[b]{2}{*}{ Percentile } & \multicolumn{2}{|c|}{ Returns } & \multicolumn{2}{|c|}{ Sharpe ratios } & \multicolumn{2}{|c|}{ Option prices } \\
\hline & CA (\%) & IA (\%) & CA & IA & CA (\%) & IA (\%) \\
\hline \multicolumn{7}{|c|}{ Panel A: 1989-2003 } \\
\hline 5 & 1.5 & 1.7 & 9.2 & 9.5 & 2.0 & 2.9 \\
\hline 25 & 0.8 & 0.7 & 3.8 & 3.9 & 1.6 & 2.4 \\
\hline 75 & -0.7 & -0.7 & -3.9 & -3.9 & 2.3 & 2.4 \\
\hline 95 & -1.6 & -1.7 & -9.0 & -9.1 & 2.3 & 2.5 \\
\hline \multicolumn{7}{|c|}{ Panel B: 1989-96 } \\
\hline 5 & 2.1 & 1.5 & 16.4 & 11.7 & 1.7 & 1.4 \\
\hline 25 & 0.9 & 0.6 & 6.2 & 4.7 & 1.9 & 0.9 \\
\hline 75 & -0.9 & -0.6 & -6.5 & -4.8 & 1.6 & 1.7 \\
\hline 95 & -2.3 & -1.6 & -15.7 & -11.4 & 1.9 & 0.7 \\
\hline \multicolumn{7}{|c|}{ Panel C: 1997-2003 } \\
\hline 5 & 2.7 & 3.0 & 11.0 & 13.2 & 2.1 & 2.2 \\
\hline 25 & 1.1 & 1.2 & 4.5 & 5.2 & 1.4 & 1.6 \\
\hline 75 & -1.1 & -1.2 & -4.4 & -5.3 & 1.9 & 2.4 \\
\hline 95 & -2.8 & -3.0 & -11.2 & -12.6 & 2.1 & 2.1 \\
\hline
\end{tabular}

CA: Country allocation; IA: Industry allocation. Annual figures.

Table A4 Introduction of the euro, no TMT stocks

\begin{tabular}{|c|c|c|c|c|c|c|}
\hline \multirow[b]{2}{*}{ Percentile } & \multicolumn{2}{|c|}{ Returns } & \multicolumn{2}{|c|}{ Sharpe ratios } & \multicolumn{2}{|c|}{ Option prices } \\
\hline & CA (\%) & IA (\%) & CA & IA & CA (\%) & IA (\%) \\
\hline \multicolumn{7}{|c|}{ Panel A: Europe, before euro } \\
\hline 5 & 2.0 & 1.6 & 23.2 & 15.7 & 2.6 & 2.6 \\
\hline 25 & 0.8 & 0.7 & 9.0 & 6.1 & 2.0 & 1.8 \\
\hline 75 & -0.8 & -0.7 & -9.7 & -6.3 & 1.4 & 1.5 \\
\hline 95 & -2.0 & -1.6 & -21.1 & -14.6 & 2.2 & 2.2 \\
\hline \multicolumn{7}{|c|}{ Panel B: Europe, after euro } \\
\hline 5 & 2.4 & 3.1 & 10.7 & 14.3 & 1.7 & 2.1 \\
\hline 25 & 1.0 & 1.3 & 4.5 & 5.9 & 0.4 & 4.5 \\
\hline 75 & -1.0 & -1.3 & -4.4 & -5.9 & 0.9 & 1.4 \\
\hline 95 & -2.5 & -3.1 & -11.0 & -14.2 & 1.0 & 3.3 \\
\hline \multicolumn{7}{|c|}{ Panel C: EMU, before euro } \\
\hline 5 & 2.1 & 1.8 & 18.5 & 14.4 & 2.0 & 1.6 \\
\hline 25 & 0.9 & 0.7 & 6.9 & 5.5 & 1.7 & 2.8 \\
\hline 75 & -0.9 & -0.8 & -7.4 & -5.8 & 1.3 & 2.2 \\
\hline 95 & -2.2 & -1.8 & -16.9 & -13.7 & 0.9 & 1.5 \\
\hline \multicolumn{7}{|c|}{ Panel D: EMU, after euro } \\
\hline 5 & 2.8 & 3.4 & 11.3 & 13.6 & 2.4 & 0.8 \\
\hline 25 & 1.2 & 1.4 & 5.0 & 5.4 & 1.9 & 2.5 \\
\hline 75 & -1.2 & -1.4 & -4.6 & -5.4 & 2.2 & 1.5 \\
\hline 95 & -3.0 & -3.3 & -12.1 & -13.1 & 2.3 & 2.0 \\
\hline
\end{tabular}

CA: Country allocation; IA: Industry allocation. Annual figures. 


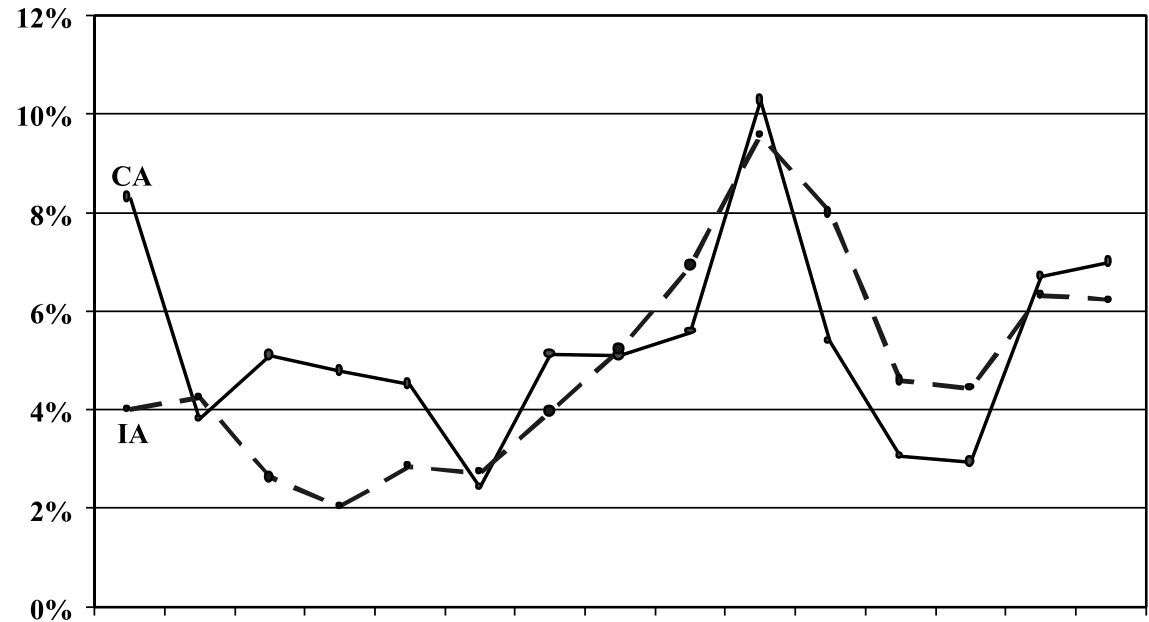

198919901991199219931994199519961997199819992000200120022003

Figure A1 EMU countries, no TMT stocks

Table A5 A hypothetical example

\begin{tabular}{lcccccc}
\hline & Year 1 (\%) & Year 2 (\%) & Year 3 (\%) & Year 4 (\%) & Year 5 (\%) & Cumulative (\%) \\
\hline Country allocation & & & & & & \\
Top & 8.8 & 17.4 & 39.4 & 4.9 & 23.8 & 18.2 \\
Bottom & 54.3 & 8.1 & 4.8 & 7.5 & 1.7 & 13.8 \\
Spread & -45.5 & 9.3 & 34.6 & -2.6 & 22.1 & 4.4 \\
Standard deviation of spread & & & & & 27.5 \\
Industry allocation & & & & & & \\
Top & 3.1 & 27.4 & 2.5 & 4.9 & 25.7 & 12.2 \\
Bottom & -15.0 & 20.7 & -14.6 & 20.0 & -5.2 & -0.1 \\
Spread & 18.1 & 6.7 & 17.1 & -15.1 & 30.9 & 12.2 \\
Standard deviation of spread & & & & & 15.4 \\
\hline
\end{tabular}

\section{The option pricing approach}

This Appendix illustrates the fact that relative dispersion between a top-percentile portfolio and a bottom-percentile portfolio will not always coincide with the relative values of options to exchange these portfolios. In this example, the top-percentile country portfolio has an annualised cumulative return of 18.2 per cent compared with 13.8 per cent for the bottom-percentile portfolio; hence, the dispersion between them equals 4.4 per cent. The dispersion between the top- and bottom-percentile industry portfolios, however, is much greater (12.2 per cent). Therefore, dispersion in returns would indicate the superiority of the industry approach.

The value of an option to exchange the top portfolio for the bottom portfolio, however, does not depend on the dispersion of their cumulative performance, but rather on the volatility of the time series of their net returns. The standard deviation of the net returns of the country portfolios equals 27.5 per cent compared with 15.4 per cent for the industry portfolios. Therefore, even though country selection leads to less dispersion in cumulative performance than industry selection, an option to exchange top- and bottom-percentile performance is more valuable for country portfolios than for industry portfolios. 